\title{
Aportes de la Educación Religiosa escolar al cultivo de la espiritualidad humana ${ }^{1}$
}

Sonia Alejandra Naranjo Higuera

orcid.org/0000-0001-8735-5602 Universidad Santo Tomás, Bogotá sonianaranjo@ustadistancia.edu.co

\section{Ciro Javier Moncada Guzmán}

orcid.org/00oo-0003-0796-9546 Universidad Santo Tomás, Bogotá ciromoncada@ustadistancia.edu.co

\section{Resumen}

Este artículo es resultado de un proyecto de investigación interinstitucional construido con un enfoque cualitativo y métodos narrativos en ocho ciudades principales de Colombia, con la intención de indagar por la naturaleza y las prácticas pedagógicas de los docentes de Educación Religiosa Escolar (ERE), área presentada como fundamental y obligatoria por la Ley General de Educación. Los relatos de los docentes abordados evidenciaron diversas perspectivas respecto a la identidad y la praxis de la ERE, pero dentro de estos enfoques fue de interés para los investigadores una prospectiva emergente de su desarrollo en tanto búsqueda por el cultivo de la dimensión espiritual del ser humano. Ello motivó a que este escrito se planteara como objetivo dar a conocer algunos aportes que la Educación Religiosa Escolar puede brindar al cultivo de la espiritualidad humana, pues se evidenció que una ERE construida desde esta perspectiva no solo favorece el pluralismo religioso y evita cualquier tipo de exclusión por motivos de algunas dinámicas de los sistemas religiosos mayoritarios, sino que, además, es una oportunidad para configurarla como aporte a la formación integral a partir del favorecimiento de escenarios educativos que posibiliten las búsquedas, las construcciones y el cultivo del sentido de la vida humana.

\section{Palabras clave (Fuente: tesauro de la UnEsco)}

Educación religiosa; inteligencia espiritual; religión; espiritualidad; estudios de la religión.

$1 \quad$ Este artículo es resultado de la investigación interinstitucional "La ERE como disciplina escolar" de la Universidad Santo Tomás de Aquino de Bogotá y la Fundación Universitaria Católica Lumen Gentium de Cali, 2017-2018.

Recepción: 02/06/2018 | Envío a pares: 11/08/2018 | Aceptación por pares: 07/09/2018 | Aprobación: 09/03/2019 


\title{
Contributions of Religious Education in School to Cultivating Human Spirituality ${ }^{1}$
}

\begin{abstract}
This article derives from an interinstitutional research project built, which took a qualitative approach and was conducted in eight major cities of Colombia using narrative methods. It aimed to inquire into the nature and pedagogical practices of Religious Education teachers, which is a fundamental and mandatory class under the General Education Act. Accounts of participating teachers showed different outlooks as to the identity and praxis of Religious Education in School (RES) but, within them, researchers' interest focused on an emerging perspective that regards this subject as a search for the cultivation of human spirituality. Therefore, this paper intends to present some contributions that RES can make to cultivate human spirituality because, when built from this perspective, it favors religious pluralism - preventing any exclusion arising from the dynamics of majority religious systems- and enriches comprehensive education by providing educational opportunities for the search, construction and cultivation of the meaning of human life.
\end{abstract}

\section{Keywords (Source: UnEsco Thesaurus)}

Religious education; spiritual intelligence; religion; spirituality; religion studies.

1 This article is the result of the interinstitutional research "RES as a School Subject" by the Universidad Santo Tomás de Aquino in Bogotá and the Fundación Universitaria Católica Lumen Gentium in Cali, 2017-2018. 


\section{Contribuições do Ensino Religioso escolar para preservar a espiritualidade humana ${ }^{1}$}

\section{Resumo}

Este artigo é resultado de um projeto de pesquisa interinstitucional construído com uma abordagem qualitativa e executado por métodos narrativos em oito cidades principais da Colômbia, com o intuito de questionar sobre a natureza e as práticas pedagógicas dos professores de Ensino Religioso Escolar (ERE), área apresentada como fundamental e obrigatória pela Lei Geral de Educação. Os relatos dos docentes abordados evidenciam diversas perspectivas a respeito da identidade e da práxis do ERE, mas, dentro dessas abordagens, foi de interesse para os pesquisadores uma prospectiva emergente quanto a seu desenvolvimento no que se refere à busca por preservar a dimensão espiritual do ser humano. Isso motivou a que este texto fosse proposto como objetivo de divulgar algumas contribuições que o ERE pode oferecer à preservação da espiritualidade humana, pois se evidenciou que um ERE construída sob essa perspectiva não somente favorece o pluralismo religioso, ao evitar qualquer tipo de exclusão por motivos de algumas dinâmicas dos sistemas religiosos predominantes, mas também é uma oportunidade para configurá-lo como contribuição para a formação integral a partir do favorecimento de cenários educativos que possibilitem as buscas, as construções e o cultivo do sentido da vida humana.

\section{Palavras-chave (Fonte: Tesauro da Unesco)}

Educação religiosa; inteligência espiritual; religião; espiritualidade; estudos de religião. 
Es posible evidenciar en las epistemologías y en las dinámicas sociales actuales una tendencia al rescate, la visibilización y la valoración de la diferencia y el pluralismo en diversos sentidos, no solo desde perspectivas culturales, sino también en escenarios que antes se consideraban exclusivamente privados. La configuración religiosa del ser humano no ha escapado a dicha tendencia y se configura como un foco de atención que reclama la concreción de políticas públicas, que rescaten la importancia de la diversidad religiosa en prospectiva de la construcción de posturas pluralistas, que posibiliten no una tolerancia obligada, sino la comprensión de la riqueza en la pluralidad.

Ha habido intentos legislativos por concretar en la escuela colombiana la tarea de la construcción de posturas pluralistas en el ámbito religioso. Tal es el caso de la Constitución Política de 1991, que presenta al país como una república pluralista (art. 1) que asigna a la educación la tarea de una formación integral (Ley 115, 1994, art. 5, num. 2), de tal forma que la educabilidad del respeto por la diversidad religiosa tenga lugar en la escuela (Ley 133, 1994, art. 6, lit. h), sin estar cerrada a una única confesionalidad (Decreto 354, 1998, art. 7), pues, por el contrario, debe propender por el desarrollo de la espiritualidad del ser humano (MEN, 1998, p. 74), la apuesta por la concepción integral de la persona desde la dimensión trascendente (Decreto 4500, 2006, art. 3) y la dimensión espiritual (Ley 115, art. 5, num. 1; Decreto 1075, 2015, art. 1.1.1.1., num. 6).

A pesar de estos lineamientos, que señalan la importancia del pluralismo religioso, la espiritualidad y la dimensión trascendente del ser humano dentro de la Educación Religiosa Escolar, algunas prácticas pedagógicas cotidianas evidencian cierto apego por la consolidación de la catequesis y otros procesos evangelizadores dentro de las dinámicas escolares, de tal forma que fácilmente la ERE es confundida como un lugar para la Pastoral Educativa, una tendencia que responde más a las lógicas heredadas de la bula Inter Caetera (1493) y la Constitu- ción de 1886, que incluso en su época ya habían sido cuestionadas por el Decreto Orgánico Instrucción Pública de 1870 respecto al lugar del proselitismo religioso en la escuela.

Ante este panorama, este artículo se ha planteado como objetivo dar a conocer algunos aportes de la Educación Religiosa al cultivo la espiritualidad humana, pues se evidenció que esta categoría permite un diálogo académico y existencial que posibilita la construcción de un área escolar abierta al pluralismo religioso en el marco de la dinamización de la formación integral del ser humano. Por ello, se realizó un trabajo de campo a través de métodos narrativos, el cual fue acompañado de una fundamentación teórica del concepto de lo espiritual.

Para cumplir con este objetivo, y luego de una breve presentación del diseño metodológico de la investigación, este artículo construye una aproximación conceptual a la comprensión de la epistemología de la espiritualidad con fundamento en los estudios de la religión, los cuales posibilitan la intelección de lo espiritual en el ser humano como pilar en la construcción de la dimensión trascendente, el pluralismo religioso y, si el sujeto opta libremente, el fortalecimiento de su confesionalidad a partir del acto libre y consciente. En un segundo momento, se delimita la inteligencia espiritual como una categoría emergente que pretende señalar la condición de posibilidad humana por dar respuesta a la búsqueda de sentido, para que, en tercer lugar, puedan discutir las posibles vinculaciones entre la espiritualidad y la ERE como área obligatoria del currículo colombiano.

\section{Ruta metodológica}

El trabajo de campo fue realizado durante el primer semestre del año 2017 con 33 docentes en 8 ciudades de Colombia, a saber: Barranquilla, Bogotá, Bucaramanga, Cali, Manizales, Medellín, Pasto y Pereira, los cuales desarrollan su ejercicio pedagógico en colegios públicos y privados. Para ello, se realizó un trabajo colaborativo entre los investigadores de 
la Universidad Santo Tomás de Bogotá y la Fundación Universitaria Católica Lumen Gentium de Cali.

El enfoque de investigación de este ejercicio fue el cualitativo, teniendo en cuenta que entre "los rasgos más característicos de la investigación cualitativa se encuentran: a) el interés por el significado y la interpretación, b) el énfasis sobre la importancia del contexto y los procesos, y c) la estrategia inductiva y hermenéutica" (Vasilachis, 2004, p. 26). Es así como el centro de esta investigación propone indagar por los significados profundos que los docentes dan a su práctica pedagógica de la Educación Religiosa, de tal forma que el énfasis está en la interpretación de la cultura escolar desde las subjetividades abordadas.

Para cumplir con este horizonte, se planteó como perspectiva epistemológica la hermenéutica, la cual permitió una lectura interpretativa de la práctica pedagógica a partir de los relatos expuestos por los docentes que colaboraron en la investigación, ya que "el que quiere entender un texto está dispuesto a dejarse enseñar por él. Por ello una conciencia hermenéutica adiestrada tiene que ser sensible desde el primer momento a la alteridad del texto" (Gadamer, 1999, p. 478). El ejercicio investigativo sostuvo como horizonte la interpretación de las diversas intencionalidades de los relatos de los docentes, donde cada uno exige la comprensión de las condiciones contextuales, así como la relacionalidad que surge de las diferentes categorías que iban emergiendo de las narrativas; de esta forma, las técnicas de análisis de información quedan configuradas en la triangulación hermenéutica de la información recogida (Cisterna, 2015, p. 68).

El tipo de investigación asumido fue el método narrativo, ya que la "construcción de la identidad docente, la relación pedagógica, el alumnado, la experiencia educativa y de aprendizaje, la inclusión, la construcción de una comunidad educativa y la participación, son ámbitos importantes en la investigación narrativa para contribuir al cambio educativo" (Márquez, Prada y Prados, 2017, p. 18). Las narraciones permitieron visibilizar las diversas realidades de los docentes, de tal forma que la reflexión del ejercicio pedagógico cotidiano pudo mostrar elementos característicos de la praxis de la ERE en el contexto colombiano, rutas epistemológicas que dieron respuesta a la necesidad de fundamentación de la identidad de la Educación Religiosa Escolar.

En cuanto a la técnica de recolección de información, fue necesaria la recopilación de las historias de vida de los docentes, donde "el investigador debe obtener datos completos y profundos sobre cómo ven los individuos los acontecimientos de sus vidas y a sí mismos [...] una reflexión retrospectiva sobre sus experiencias en torno a un tema o aspecto" (Hernández et al., 2010, p. 437). Además, surgió la necesidad de realizar diversos análisis de documentos especializados, los cuales "tienen como objetivo presentar en forma condensada el contenido de un documento o informe de investigación; su característica es la de reflejar el contenido del documento original, su extensión es variable y depende de la complejidad del informe o documento" (Tamayo, 2004, p. 301). De esta forma, las narraciones y las búsquedas teóricas se construyeron a partir de cuatro categorías de reflexión para esta investigación: naturaleza, currículo, didáctica y evaluación de la Educación Religiosa.

Por último, los instrumentos de recolección de la información usados en este ejercicio fueron tres, a saber: en primer lugar, matrices documentales, las cuales posibilitaron el análisis de diversos textos académicos de peritos respecto a las categorías centrales de la investigación; en segundo lugar, entrevistas semiestructuradas que posibilitaron la construcción de los relatos de vida de las prácticas pedagógicas de los docentes; y por último, encuestas sobre conocimientos, actitudes y prácticas (CAP), que permitieron la caracterización de las comunidades educativas de los docentes abordados. Fueron en total 30 participantes distribuidos en ciudades como Bogotá, Pasto, Bucaramanga, Barranquilla, Cali, Manizales, Pereira y Medellín. 


\section{Discusión de resultados}

Las narrativas de los docentes en las ocho ciudades permitieron evidenciar cinco tendencias de sus prácticas pedagógicas, las cuales configuraban la identidad de la ERE a partir de ciertos conceptos abordados, los cuales son resumidos en la Tabla 1.

Estas cinco tendencias pueden ser evidenciadas en los siguientes fragmentos que resaltan las diversas comprensiones que tienen los docentes del ejercicio de la Educación Religiosa Escolar en sus aulas (Tabla 2).
Es evidente la ambigüedad en las narraciones de los docentes, en parte, quizás, por la naturalización del lenguaje, principalmente marcado por el catolicismo popular (Beltrán, 2013, p. 71) o, en parte, por el apego a la catequesis dentro de la escuela, y aunque algunos autores, como Mario Peresson (2004, 2016), José Luis Meza et al. (2011, 2013, 2015), J. L. Meza y G. Suárez (2018), Elizabeth Coy (2009, 2010), Isabel Corpas (2012), Jaime Laurence Bonilla (2015), Dayro Botero y Álvaro Hernández (2017), ya han criticado esta postura pedagógica, los relatos la muestran como la más representativa en las escuelas diagnosticadas.

Tabla 1. Tendencias de las prácticas pedagógicas de la ERE

\begin{tabular}{|c|c|c|c|c|}
\hline Catequesis & Humanismo & Hecho religioso & Trascendencia & Espiritualidad \\
\hline Evangelio & Valores & Ecumenismo & Trascendencia & Sentido de vida \\
\hline Fe & Deberes & Diversidad & Alteridad & Existencia humana \\
\hline Reino de Dios & Derechos & Pluralismo & Sentido social & Introspección \\
\hline Sacramentos & Convivencia & Tolerancia & Apertura & Espiritualidades \\
\hline Jesucristo & Diálogo & Expresiones de fe & Existenciales & \\
\hline Biblia & Integralidad & Identidad religiosa & Lo absoluto & \\
\hline Iglesia & Bien común & Historia de las religiones & & \\
\hline Teología práctica & Cultura ciudadana & & & \\
\hline
\end{tabular}

Fuente: elaboración propia con base en las narrativas de los docentes.

Tabla 2. Narrativas de los docentes por tendencias

\begin{tabular}{|c|l|}
\hline Tendencias & \multicolumn{1}{|c|}{ Fragmento } \\
\hline Catequesis & $\begin{array}{l}\text { "Se puede decir que la ERE es un acompañamiento que hace el docente a nuestros estudiantes con } \\
\text { el fin de que ellos alcancen una madurez en el conocimiento de Dios que puedan identificar las } \\
\text { características de Cristo." (Docente 2, Pasto) }\end{array}$ \\
\hline Humanismo & $\begin{array}{l}\text { "Considero que la ERE es la que fortalece la formación humana en los estudiantes, es la que le aporta } \\
\text { al ser humano la comprensión de su historia y por tanto le invita a la transformación de la misma." } \\
\text { (Docente 1, Bogotá) }\end{array}$ \\
\hline Hecho religioso & $\begin{array}{l}\text { "Como disciplina nos lleva a indagar sobre la concepción del hecho religioso, donde se descubre el } \\
\text { proceso del hombre a través de la historia y la búsqueda de su transcendencia." (Docente 2, Cali) }\end{array}$ \\
\hline Trascendencia & $\begin{array}{l}\text { "Preguntarse por la razón de aquello trascendental que las ciencias exactas no han podido responder } \\
\text { independientemente de la denominación religiosa en que se enmarque, entonces creo que debe } \\
\text { ser una ciencia universal que permita al ser humano acercarse a eso trascendental." (Docente 6, } \\
\text { Manizales) }\end{array}$ \\
\hline Espiritualidad & $\begin{array}{l}\text { "La ERE es esa área, esa área que se encarga de acompañar los procesos de la dimensión espiritual } \\
\text { humana." (Docente 1, Medellin) }\end{array}$ \\
\hline
\end{tabular}

Fuente: elaboración propia con base en las narrativas de los docentes. 
Las otras perspectivas fueron minoría, y aunque ya es interesante saber que hay docentes que se piensan la Educación Religiosa partiendo de otros lugares epistemológicos, no deja de ser inquietante saber que la ERE es un lugar de exclusión escolar para aquellos padres de familia y estudiantes que no comparten la postura del sistema religioso mayoritario en Colombia. Es así que este artículo abordó solo una de estas tendencias, incluso la menor estadísticamente hablando, para que a partir de ella se pueda mostrar otro lugar de construcción de la ERE, donde no haya discriminaciones religiosas y se propenda por una formación integral desde una dimensión que le concierne a todo ser humano: la espiritual.

Por ello, se realiza en primer lugar un intento de construcción de una epistemología de la espiritualidad que permita aproximarse a una comprensión de dicha dimensión humana. Es necesario anotar que, junto con el concepto de espiritualidad, emergió también el concepto de inteligencia espiritual como una apuesta epistemológica de algunos sectores académicos, por lo cual se presenta además una aproximación teórica al respecto, para que, al final, pueda hablarse del aporte de la ERE a la construcción de la espiritualidad humana.

\section{Aproximación a la epistemología de la espiritualidad}

Conceptos como fe, espiritualidad, experiencia religiosa, religión y confesionalidad son usados comúnmente en el lenguaje coloquial con sentido semántico casi equivalente, como si se tratara de sinónimos; de hecho, en muchos textos académicos pareciera que la confusión es generalizada, y al confrontar las narrativas de los docentes, la intuición se hace más fuerte, pues se habla y se narra la praxis pedagógica intercambiando el sentido propio de cada uno de los conceptos, lo que se traduce en una confusión más fuerte entre el campo de acción de la ERE.

Así, antes de intentar la construcción de un currículo, unos lineamientos o estándares curricu- lares, una didáctica o incluso una perspectiva de evaluación para la Educación Religiosa en Colombia, urge comprender el corpus epistemológico que la sostiene, y aunque dicha tarea ha sido abordada por varios autores en las últimas décadas -Peresson (2004, 2016), Meza et al. (2011, 2013, 2015), Meza y Suárez (2018), Coy (2009, 2010), Corpas (2012), Bonilla (2015), Botero y Hernández (2017), entre otros-, las prácticas pedagógicas señalan todavía cierta confusión e incluso contradicción con el marco normativo colombiano.

La Educación Religiosa Escolar, en el contexto colombiano, es una disciplina obligatoria y fundamental para la formación integral, a la que apuesta la educación del país. Los diferentes desarrollos epistemológicos, teóricos, prácticos e investigativos que ha tenido, desde la década de los 9o, han permitido que hoy podamos proponer un corpus propio, teniendo como base su objeto de estudio, a saber: el despliegue de sus dimensiones espiritualy trascendente, y el desarrollo de la inteligencia espiritual de la persona. (Boteroy Hernández, 2017, p. 135)

Esta afirmación emerge del marco normativo que rige los procesos educativos del país, pero no será tarea de este artículo señalar las especificidades epistemológicas de cada uno de los componentes que allí se señalan, sino de dos, que, por su actualidad y necesidad, son pertinentes para la fundamentación epistemológica de la ERE: la espiritualidad y la inteligencia espiritual. La intención de hacer una epistemología de la espiritualidad no es practicar una separación aséptica de lo espiritual con respecto a lo religioso ni tampoco concluir que es un área innecesaria en la escuela. La idea es mostrar el estado de la cuestión respecto a la discusión académica, entendiéndola como un lugar de formación integral que da al ser humano un marco de sentido que no se reduce a unos sistemas religiosos específicos y, en cambio, aporta a toda la plataforma antropológica de la humanidad. 
Para comprender la dimensión espiritual en el contexto antropológico de la cotidianidad humana y del devenir al cual está inscrito, es necesario contextualizar el marco histórico que hace posible pensar en la actualidad este nuevo discurso que, como categoría emergente, ha aparecido en la agenda académica de los últimos años a través de diversas investigaciones sobre el sentido de vida del ser humano. Son los estudios de la religión y la espiritualidad quienes han hecho el camino propedéutico a la reflexión epistemológica de lo religioso y lo espiritual del hombre, pues, como fenómeno humano, ambos son testimonio de las búsquedas, respuestas y construcciones de sentido que a lo largo de la historia ha desarrollado el hombre (Grondin, 2010, p. 13).

Las reflexiones, conclusiones y cuestiones abiertas de orden epistemológico, sin intereses de tipo proselitista acerca de la religión y la espiritualidad, están en una etapa de resurgimiento con los aportes de las ciencias de la religión (Sánchez, 2003, p. 28), pues, aunque la filosofía y la teología ya contaban en la Edad Media con desarrollos teóricos del fenómeno religioso, lo hacían desde un espectro delimitado, ya sea por su intencionalidad o por el sistema religioso que las orientó. Este escrito abordará esta pretensión epistemológica con el nombre de estudios de la religión y la espiritualidad, en cuanto son esfuerzos académicos con un objeto de estudio común: lo religioso, lo trascendente y lo espiritual en el hombre, evidenciado a través de fenómenos humanos que son susceptibles de análisis, comprensión, interpretación y evaluación, no en el sentido positivo estrictamente dicho, pues no solo son estudiados por el método científico, sino como lugares de reflexión amplios y no reductibles a una mirada fragmentada de las realidades del hombre (Sánchez, 2003, p.42).

El aporte principal de estos estudios, ya sean de tipo histórico-descriptivo, empírico-analítico, hermenéuticos, critico-sociales o más contextuales, es la visibilización del salto cualitativo en el desarrollo y la construcción de la vida humana, donde se evi- dencia el paso del asombro al desarrollo del sentido de la vida. Para efectos de este escrito, se concentrará la atención en intentar una epistemología de la espiritualidad, de tal forma que se evidencie un fundamento antropológico que permita la distinción entre lo que podría comprenderse por espiritual.

El intento por conceptualizar y caracterizar lo espiritual ha sido un ejercicio en el que subyacen diversas tendencias y perspectivas a lo largo de la historia. Es asi que es posible narrar aproximaciones a la epistemología de la espiritualidad con base en ejercicios lingüísticos, como la etimología; en la filosofía, con construcciones discursivas elaboradas; en la teología, con elaboraciones fundadas en algunos sistemas religiosos; en la psicología, con interpretaciones conductuales; en la sociología y la fenomenología de la religión, con desarrollos orientados por la epistemología mitológica; y en otros estudios que resaltan diversos aspectos de lo espiritual en la cotidianidad del ser humano.

En primer lugar, la etimología del concepto espíritu permite una primera aproximación para la comprensión de lo que podría entenderse por espiritualidad. Al respecto, Enric Benavent señala:

El concepto espiritualidad va más allá de creer en seres inmateriales o sobrenaturales. [...] La palabra -espiritu- no se refiere a ninguna de estas creencias. En latín, spiritus se refiere al aliento vital, a la fuerza para vivir (de la misma forma que el griego pneuma, el hebreo ruah, del sánscrito prana o el chino qui). Podemos utilizar "espiritu" para referirnos a todo aquello que da vitalidad, sentido y trascendencia, algo estrechamente vinculado al bienestar de la persona. (2003, p. 12)

De esta forma, lo espiritual queda comprendido en el marco del aliento de la vida humana, es decir, en las condiciones de posibilidad de la misma vida del hombre, aquello que se constituye como el principio vital del ser humano y lo caracteriza como viviente, en contraposición a lo inerte, para luego 
poder proyectarse también a lo trascendente. Así las cosas, hablar de espiritualidad es hablar del desarrollo y despliegue de ese principio vital a través de la búsqueda de sentido de la vida, con miras al bienestar personal.

Esta base lingüística da fundamento a la reflexión desde la epistemología mítica de Marià Corbí, que, apoyado en hallazgos sociológicos y fenomenológicos, señala que la interpretación de la dimensión absoluta de la realidad, aquella que prescinde de nuestras necesidades, depende de cada cultura humana, pues ella emerge como despliegue natural de la programación de la sociedad, de tal forma que recolectores, cazadores, agricultores, ganaderos, industriales y la sociedad del conocimiento actual construyen comprensiones de lo que es la vida y cómo hay que vivirla y sentirla a partir de relaciones concretas como vida-muerte o mandatoautoridad. "Si llamamos a la iniciación y cultivo de la dimensión absoluta de la realidad 'espiritualidad', habrá que concluir que en las sociedades dinámicas la espiritualidad será imposible si no se diferencia con toda claridad la copa -que es de nuestra exclusiva responsabilidad-del vino" (Corbí, 2007, p. 149).

Con la analogía de la copa y el vino, el autor señala que la iniciación y el cultivo de la dimensión absoluta de la realidad se ha construido culturalmente a partir de la experiencia histórica de la humanidad con sus diversas realidades, por ello las copas hacen las veces de estos constructos, unas estructuras de programación que han servido para configurar la forma de vivir y sentir el mundo. Sin embargo, el vino es siempre el mismo: es la dimensión absoluta que toma la forma de la copa de acuerdo con la cultura que ha construido dicho artefacto. Su invitación es a superar las religiones por una nueva espiritualidad laica (nueva copa), sin dioses ni creencias, postura demasiado radical.

La forma de afrontar la vida ha sido también objeto de estudio de la filosofía, pues para autores como Pierre Hadot la filosofía es una forma de vivir: "entendía la filosofía como una metamorfosis ab- soluta de la manera de ver el mundo y estar en él" (2006, p. 17). Por ello el autor habla de la praxis de la filosofía antigua como "ejercicios espirituales", debido a que "la palabra espiritual permite comprender con mayor facilidad que unos ejercicios como estos son producto no solo del pensamiento, sino de una totalidad psíquica del individuo que, en especial, revela el auténtico alcance de tales prácticas: gracias a ellas el individuo accede al círculo del espíritu objetivo, lo que significa que vuelve a situarse en la perspectiva del todo" (p. 24).

La transformación de la personalidad es una tarea espiritual que la filosofía puede desarrollar, siempre y cuando esta sea vista como la invención de la vida desde la realización y la mejora de cada uno. Los ejercicios espirituales posibilitan la modificación del paisaje interior del sujeto, al mismo tiempo que transforman su visión del mundo, es decir, engloban una conversión entera del sujeto humano a partir de las nuevas comprensiones de lo que es vivir, las cuales lo emancipan de las alienaciones encontradas en la cotidianidad.

Michael Foucault es cercano a esta postura. En la Hermenéutica del sujeto aborda el intento por definir qué es la espiritualidad de forma similar: "Denominaremos por tanto espiritualidad al conjunto de estas búsquedas, prácticas y experiencias entre las cuales se encuentran las purificaciones, la ascesis, las renuncias, las conversiones de la mirada, las modificaciones de la existencia que constituyen, no para el conocimiento sino para el sujeto, para el ser mismo del sujeto, el precio a pagar para tener acceso a la verdad" (1987, p. 38). Pone en el centro la necesidad del conocimiento de sí mismo, de tal forma que, para acceder a la verdad, el hombre debe transformarse en algo distinto, posibilidad que brinda la espiritualidad, pues ella surge cuando la ascesis funciona como "transfiguración del modo de ser del sujeto a través del saber" (p. 93). La verdad será entonces quien ilumine al sujeto, no en tanto cúmulo de conocimientos, sino en tanto condición de posibilidad de perfección del hombre. 
Por otra parte, André Comte-Sponville afirma que la espiritualidad es la función más elevada del ser humano, pues "somos seres finitos abiertos al infinito [...] seres efímeros abiertos a la eternidad; seres relativos abiertos al absoluto. Esta apertura es el espíritu mismo. La metafísica consiste en pensarla; la espiritualidad, en experimentarla, ejercerla, vivirla" (2006, p. 145). Así las cosas, la espiritualidad es condición de posibilidad de las diversas religiones, pero no a la inversa, incluso quienes no profesen religión pueden ejercer su propia espiritualidad, pues esta es apertura a lo absoluto. De esta forma, la espiritualidad puede convivir con las religiones como con el mismo ateísmo, pues no se trata de una superación de estadios, sino de la forma de concebir, buscar y construir el sentido de la vida humana a través del proyecto espiritual personal.

Desde la perspectiva de la Teología Cristiana, la espiritualidad podría definirse a partir de la triple función integradora de la identidad de la persona desde su opción fiducial a través del camino al interior, a la trascendencia y al otro. Sus características responden a las lógicas de la experiencia de la fe, la vida en el espíritu, el contacto con el mundo, la felicidad, el diálogo, el realismo, la fraternidad, la comunidad, el afecto, la relación con el misterio y la experiencia pascual (Gamarra, 1994). En esta perspectiva es notorio el sesgo hacia sus dinámicas religiosas, de tal forma que se reduce lo espiritual a la experiencia religiosa pascual, pues se hace depender la dimensión del sentido a una única perspectiva confesional.

Un autor cercano al contexto colombiano, Gerardo Remolina, define el espíritu como la interioridad del ser humano en tanto que el hombre tiene la capacidad de encuentro consigo mismo para tomar conciencia de sí, ya que el hombre no solo es cuerpo (realidad física), sino también alma (principio vital, función de intermediación) y espíritu (subjetividad e interioridad), donde esta última le posibilita la construcción del significado de la vida (2017, p. 288). Con dicho fundamento antropológico, define a la espiritualidad como:
El cultivo del espiritu, de la vida interior. Un cultivo que consiste en proporcionarle al espiritu la atención y los cuidados necesarios para su conservación y desarrollo. Hay muchos métodos y formas de espiritualidad. Dichos métodos combinan los aspectos corporales, (ejercicios físicos como el yoga y el zen), los aspectos fisiológicos (como el dominio y regulación de la respiración), los aspectos psicológicos (como el vacío de la imaginación y el pensamiento, como en el budismo), y ejercicios directamente espirituales (como la concentración mental y las variadas formas de meditación, oración y contemplación). (p. 289)

Entonces, la experiencia religiosa puede entenderse a partir de las diferentes configuraciones culturales que se han dado en la historia de la humanidad de acuerdo con las circunstancias de los hombres y mujeres, pero ha sido la espiritualidad quien le ha servido de fundamento, pues las búsquedas y construcciones de significativo desde la interioridad lo han permitido. Con esto, el autor no defiende un aislamiento subjetivo o cierto individualismo; por el contrario, resalta que la búsqueda propia del cultivo de la vida interior hace tomar conciencia del cuidado de la humanidad.

Por último, autores como Camino Cañón Loyes y Jordi Font han construido "estados de la cuestión" respecto a cómo se podría comprender la espiritualidad desde una perspectiva naturalizada:

La búsqueda de sentido realizada por los humanos a la que llamamos espiritualidad, constituye un proceso en la historia que se ha descrito de múltiples maneras: como estados de consciencia logrados por el primate evolucionado (Harris), como un intento de responder a la perplejidad de sabernos mortales, contingentes, irrelevantes y, al mismo tiempo, únicos, lúcidos, con relatos de sentido sobre el sentido (Moya), como la dimensión del vivir humano que abre a dimensiones que están más allá del mundo (Wittgenstein), la experiencia del sujeto que se 
dispone a entrar en relación interior con algo invisible pero que es una realidad que le atrae (Font) o la vivencia que abre al Misterio al que reconoce como fuente de armonía, de paz, de belleza, de bien, de amor. (Cañón, 2017, p. 610)

Desde el punto de vista antropológico, la vida espiritual es un proceso vital, psicobiológico evolutivo, hacia la maduración de la persona humana en el que distinguimos: el proceso evolutivo madurativo, de la vida humana, en el que la espiritualidad es una emergencia de la vida cuya maduración no acaba, [pues] trasciende el ciclo vital. Es una dimensión que no se agota con el ciclo vital, hay una dimensión que lo trasciende y tiende hacia una relación de unidad total, en una vivencia no-dual. (Font, 2017, p. 633)

Aparece la necesidad de superar los reduccionismos lingüísticos acerca de la espiritualidad, al minimizar su núcleo ontológico a la sobrenaturalidad. Urge así resignificar la espiritualidad en tanto dimensión humana que emerge cuando la mujer y el hombre propenden por buscar y construir el sentido de su vida a partir del conocimiento de sí mismos, sin individualismos, sino abiertos a la comprensión de la dimensión absoluta de la realidad, en el anhelo del encuentro con lo verdadero, para que al final surja un estilo de vida fundado en la autonomía humana sin la negación de la alteridad.

Luego entonces, hablar de epistemología de la espiritualidad es, en primera instancia, hacer la reflexión respecto del núcleo antropológico, ontológico, sociológico y psicológico que dota de apertura y sensibilidad al individuo, por la búsqueda de sentido a partir de su experiencia cotidiana que se proyecta hacia una plenitud existencial que rebasa lo sensible, sin desconocerlo, y sin que sea condición de posibilidad ni sinónimo exclusivo de una vinculación fiducial a un sistema religioso; en segunda instancia, la epistemología de la espiritualidad pregunta por el corpus de conocimientos que permite hablar de la espiritualidad como aporte a la construcción del proyecto humano en comunidad.

\section{Aproximación epistemológica a la inteligencia espiritual}

Antes de intentar una exposición del concepto de Inteligencia Espiritual, es necesario definir qué se va a entender por inteligencia. Howard Gardner expresó alguna vez en una entrevista que la inteligencia "es un potencial bio-psicológico, lo que significa que es parte de nuestro cerebro y de nuestra mente -que no son lo mismo-, para resolver problemas reales, para hacer cosas que son valoradas en, cuando menos, una cultura o comunidad, y para encontrar o crear nuevos retos" (2010). El significado que le da Gardner a la inteligencia parte de lo biológico y psicológico de la persona, es decir, lo natural de su ser que aparece como la capacidad de enfrentar y resolver las situaciones que se presentan en la cotidianidad, y que, a su vez, posibilitan el desarrollo de nuevas habilidades humanas y la construcción de su cultura.

Francesc Torralba (2015) señala distintas acepciones del concepto inteligencia: es "leer dentro", es la capacidad de elegir entre diversas opciones, de adaptarse a entornos distintos y de hallar soluciones. Es evidente entonces que la inteligencia no se reduce a lo cognitivo, sino a un amplio espectro de acciones humanas en pro de la resolución de situaciones simples o complejas, lo cual conduce al ser humano a desarrollar múltiples habilidades, plataforma que permitiría hablar no de una única inteligencia, sino de varias, perspectiva postulada directamente por Gardner con su teoría de inteligencias múltiples.

Las inteligencias múltiples se evidencian en el desarrollo personal del sujeto y el contacto con su contexto cultural y social: "lingüística, musical, lógico-matemática, corporal y kinestésica, espacial y visual, intrapersonal, interpersonal e inteligencia naturista o ecológica" (Gómez, 2011, p. 22). Estas, a su vez, posibilitaron un giro epistemológico con relación a 
la interpretación de lo que significa ser inteligente. Por ello otros autores han continuado y ampliado la discusión. Es el caso de Daniel Goleman (1995), con su propuesta de la inteligencia emocional; de Gardner, quien habla de inteligencia existencial, entendida como la "capacidad de la especie para insertarse en cuestiones trascendentales" (2001, p. 69); de José María Doria, con la inteligencia transpersonal (2013); o de Pierre Levy, con la inteligencia colectiva (1994) que hace otro tipo de lectura desde la cultura digital; y, finalmente, la que atañe a este apartado: la inteligencia espiritual, que según Danah Zohar e lan Marshall es aquella "con que afrontamos y resolvemos problemas de significado y valores, la inteligencia con que podemos poner nuestros actos y nuestras vías en un contexto más amplio, más rico y significativo, la inteligencia con que podemos determinar que un curso de acción o un camino vital es más valioso que otro" (2001, p. 19).

Zohar y Marshall definen espiritual como el principio animado y vital del hombre, el soplo de la vida que, unido a la necesidad humana de preguntarse por las cuestiones fundamentales o sustanciales, lleva al individuo a hallar el sentido y el valor de lo que se hace y experimenta en la cotidianidad. Por ello se hace evidente en la toma de decisiones, a la hora de afrontar el bien y el mal, de dar límite a las acciones e, incluso, al apoyar el funcionamiento intelectual y emocional, ya que los articula con el contexto concreto del diario vivir.

Por su parte, Francesc Torralba afirma que existen ciertas preguntas que llevan a la mujer y al hombre a cuestionarse continuamente sobre su realidad personal: ¿quién soy yo?, ¿qué será de mí?, ¿de dónde vengo?, ¿cuál es el sentido de la vida?, ¿cuál es mi misión en la vida?, ¿por qué existen las cosas?, ¿dónde está Dios? (2010, p. 71). Estas preguntas no solo mantienen al ser humano en un constante estado de cuestionamiento sobre su existencia, sino que a la vez son la plataforma desde la cual "la inteligencia espiritual faculta para tener y anhelar una visión de la vida y de la realidad que integre, conecte, trascien- da y dé sentido a la existencia" (p. 21). Entonces, ella posibilita el desarrollo de capacidades de autoconocimiento que permiten la construcción de la identidad a partir de la reflexión y la toma de decisiones en prospectiva del crecimiento de la interioridad.

La utilizamos para lidiar con problemas existenciales, problemas con que nos sentimos atascados, atrapados por nuestros propios hábitos del pasado o por neurosis o problemas de enfermedad y desdicha. La Inteligencia espiritual nos hace conscientes de que tenemos problemas existenciales y nos permite resolverlos o al menos encontrar una cierta paz pese a ellos. Nos da un sentido profundo sobre la lucha por la vida. (Zohary Marshall, 2001, p. 27)

La inteligencia espiritual permite al ser humano empoderarse de su existencia a partir del ejercicio de la construcción de sentido y la dotación de valor a la cotidianidad, pues potencia su resolución de problemas y lo conduce a la toma de decisiones más acertadas frente al bien y del mal, fortaleciendo así la responsabilidad de su opción de vida. Los autores no solo sostienen esta argumentación en la especulación filosófica, sino que, a partir de la relación interdisciplinar entre la psicología y neurología, se apoyan en autores como Freud y Jung para señalar el efecto de transformación que produce la inteligencia espiritual como una función trascendente, ya que permite integrar, unificar y transformar la cotidianidad más allá de lo instintivo y de la centralidad del ego (Zohar y Marshall, 2001, p. 22), características que es posible evidenciar en la interacción neuronal a través de diversos experimentos.

Desde esta perspectiva, la inteligencia espiritual posibilita en el ser humano ciertas capacidades para dar respuesta a los problemas de la cotidianidad. Según Gómez, parafraseando a Torralba (2010), ella desarrolla y fortalece: la indagación por el sentido de la vida, la toma de distancia, la apertura a la trascendencia, la sorpresa por la existencia, el conocimiento de sí mismo, la valoración ética, la 
experiencia estética, la conmoción ante el misterio, la visión holística de la cotidianidad, la conciencia cósmica, la comunicación, el entusiasmo de vivir, la construcción del proyecto de vida y la búsqueda de religación con lo absoluto (2011, p. 12-13).

De esta forma, el cultivo de la inteligencia espiritual se da en la creación de hábitos que conducen al ser humano a la comprensión de su vida interior, a su conocimiento personal, a la búsqueda del sentido de la vida y a la resolución de los problemas que favorece un crecimiento personal y colectivo. Estas categorías posibilitan una praxis humana que no se limita a la acción religiosa de orden confesional, sino que sostiene la estructura psicológica de cualquier hombre y mujer; por ello debe ser también tarea de la escuela la apuesta por una formación integral de la espiritualidad del ser humano.

\section{Aportes de la ERE a la espiritualidad humana}

Antes de pensar la forma en que la espiritualidad pueda ingresar al currículo escolar, se necesita la superación de las posturas pedagógicas tradicionales que reducen la educación a la trasmisión de conocimiento, pues, definido como un cultivo de la interioridad y del sentido de vida, lo espiritual propende por el autoconocimiento, la búsqueda de la verdad, la resignificación de la cotidianidad y la transformación de la identidad con miras a la resolución de los problemas del diario vivir. Por lo tanto, las habilidades que se buscarían no quedan supeditadas a conceptos ni a teorías, como tampoco a sistemas religiosos, sino a la praxis de una armonía vital evidenciada en la búsqueda y la construcción del sentido humano.

La Educación Religiosa aparece como el área pertinente para dicho cultivo, no solo porque la Ley 115 así lo dice, sino porque lo religioso (ya sea entendido como vinculación, como resignificación o como retorno) y lo trascendente (entendido desde la percepción, la comunicación, la alteridad, lo simbólico, los existenciales o lo sobrenatural) necesitan como condición de posibilidad una plataforma espiritual que los sostenga, en cuanto comprensión, búsqueda y cultivo del sentido humano evidenciado en la resolución de problemas cotidianos del vivir, sentir, expresar y transformar la misma vida durante el periodo de formación escolar.

Si se toma entonces a la ERE como el lugar para el cultivo del sentido de la vida, habría que comprender esta búsqueda en un marco holístico, que no debe ser reducido a la construcción de proyectos de vida ni a cátedras axiológicas esporádicas, sin decir que estas no sean valiosas, puesto que, con un trabajo ínter y transdisciplinar, la Educación Religiosa puede posibilitar el cultivo del conocimiento de sí, la búsqueda de la verdad, la resignificación de lo cotidiano, la resolución de problemas y la transformación de la identidad en el diario vivir a través de la pregunta por el sentido. En palabras de Frankl, ello implica comprender que "vivir significa asumir la responsabilidad de encontrar la respuesta correcta a los problemas que ello plantea y cumplir las tareas que la vida asigna continuamente a cada individuo" (1991, p. 46).

Entonces, el aporte de la ERE a la espiritualidad queda supeditado al desarrollo que esta área pueda generar respecto a la búsqueda y el cultivo del sentido, teniendo en cuenta que este último concepto es amplio. Según Jean Grondin, hay cuatro formas de comprenderlo: en tanto dirección, en tanto significado, en tanto sensibilidad y en tanto reflexión (2012, pp. 74-75). Así, la tarea de la Educación Religiosa en el marco de la escuela supera las intenciones proselitistas, pues la praxis pedagógica buscaría un núcleo humano válido para todos, sin importar sus opciones religiosas: permitir a los estudiantes un espacio de formación integral que posibilite la proyección de la vida con metas e ideales a través de la búsqueda de lo verdaderamente valioso y rico en significado, de tal forma que se fomente la sensibilidad por la vida, por el otro, por el mundo, por el uni- 
verso y, en dicho camino, se hagan conscientes de la verdad, no como cúmulo de certezas, sino como la exploración constante impulsada por el asombro hacia la comprensión del misterio.

\section{Conclusiones}

Tanto las apuestas epistemológicas como las dinámicas sociales de las últimas décadas han rescatado, por una parte, la relevancia que tiene para el ser humano la búsqueda y construcción de sentido y, por otra, la pertinencia del pluralismo religioso como respuesta a los problemas de convivencia humana. Este escrito solo ha mencionado algunos autores y escuelas que señalan distintos matices de la espiritualidad, para salvarla de los exclusivismos de algunos sistemas religiosos, no con una lógica de condena, sino de rescate de la riqueza de la diversidad étnica, cultural y religiosa -que también se puede evidenciar en Colombia-, para así dar a conocer que la búsqueda de sentido atañe a todos por igual.
Entonces, la espiritualidad puede ser entendida como la praxis natural del cultivo de la interioridad humana, no como intimismo o individualismo, sino como búsqueda del conocimiento de sí mismo y el cuidado del desarrollo personal, fundamentados en las construcciones de sentido de vida, horizonte que manifiesta la epifanía de la apertura humana a la comprensión de sus distintas realidades, de tal forma que posibilita a todos la resignificación, emancipación, vinculación y transformación de la cotidianidad, movidos por la propia autonomía y hacia la conquista de la verdad y la libertad.

En tal horizonte, la ERE puede contribuir a este cultivo a través de sus prácticas pedagógicas orientadas por una formación integral de la dimensión espiritual, la dimensión trascendente y la dimensión religiosa, sin que la opción confesional del docente o del colegio interfiera en la opción de la familia, pues, por el contrario, la ERE da la plataforma para posturas pluralistas, el rescate de la diversidad religiosa y la fundamentación de las opciones personales.

\section{Referencias}

Asamblea Nacional Constituyente (1991). Constitución Política de Colombia. Recuperado de http://www.constitucioncolombia.com/indice.php

Beltrán, W. (2013). Pluralización religiosa y cambio social en Colombia. Revista Theologica Xaveriana, 63/1 (175), 57-85. Recuperado de https://revistas.javeriana.edu.co/index.php/teoxaveriana/article/view/9303

Benavent, E. (2013). Espiritualidad y educación social. Barcelona: UOC.

Bonilla, J. (2015). Educación Religiosa Escolar en perspectiva de complejidad. Bogotá: Bonaventuriana.

Botero, D. y Hernández, A. (2017). Aproximaciones a la naturaleza y fundamentos epistemológicos de la Educación Religiosa Escolar. Cali: Unicatólica.

Cañón, C. (2017). Naturalización de la espiritualidad (1). Revista Pensamiento, 73(276), 609-629. 10.14422/pen.v73. i276.y2017.029

Cisterna, F. (2005). Categorización y triangulación como procesos de validación del conocimiento en investigación cualitativa. Revista Theoria, 14(1), 61-71. Recuperado de http://www.ceppia.com.co/Documentostematicos/INVESTIGACION-SOCIAL/CATEGORIZACION-TRIANGUALCION.pdf 
Comte-Sponville, A. (2006). El alma del ateísmo: introducción a una espiritualidad sin Dios. Barcelona: Paidós.

Congreso de la República de Colombia (1994). Ley 115 del 8 de febrero. Recuperado de http://www.mineducacion.gov.co/1621/articles-85906_archivo_pdf.pdf

Congreso de la República de Colombia (1994). Ley 133 del 23 de mayo. Recuperado de http://www.alcaldiabogota.gov.co/sisjur/normas/Norma1.jsp?i=331

Corbí, M. (2007). Hacia una espiritualidad Laica: sin creencias, sin religiones, sin dioses. Barcelona: Herder.

Corpas, I. (2012). Educación Religiosa Escolar en contextos plurales. Revista Ciencias Sociales y Religión, 14(17), 77104. DOI: $10.22456 / 1982-2650.26614$

Coy, M. (2009). Educación Religiosa Escolar ¿por qué y para qué? Franciscanum, 51(152), 49-70. Recuperado de https://revistas.usb.edu.co/index.php/Franciscanum/article/view/953

Coy, M. (2010). La Educación Religiosa escolar en un contexto plural. Revista Franciscanum, 52(154), 53-83. Recuperado de http://revistas.usbbog.edu.co/index.php/Franciscanum/article/view/943

Doria, J. (2013). Inteligencia transpersonal: Observar. Madrid: Mandala.

Font, J. (2017). Naturalización de la espiritualidad (2). Pensamiento, 73(276), 631-647. DOI: 10.14422/pen.v73.i276. y2017.030

Foucault, M. (1987). Hermenéutica del sujeto. Madrid: La Piqueta.

Frankl, V. (1991). El hombre en busca de sentido. Barcelona: Herder.

Gadamer, H. (1999) Verdad y método. Salamanca: Sígueme.

Gamarra, S. (1994). Teología espiritual. Madrid: Biblioteca de Autores Cristianos.

Gardner, H. (2001). La inteligencia reformulada. Las inteligencias múltiples en el siglo XXI. Barcelona: Paidós.

Goleman, D. (1995). Inteligencia emocional. Barcelona: Kairós.

Gómez, I. (2011). La inteligencia espiritual como oportunidad educativa en la ERE. Delegación Episcopal de Enseñanza de Zaragoza, España: Recuperado de https://innovareli.files.wordpress.com/2011/o8/o-la-inteligencia-espiritual-como-oportunidad-educativa-de-la-ere.pdf

Grondin, J. (2010). Filosofía de la religión. Barcelona: Herder.

Grondin, J. (2012). Hablar del sentido de la vida. Revista Utopía y Praxis Latinoamericana, 17(56), 71-78.

Hadot, P. (2006). Ejercicios espirituales y filosofía antigua. Madrid: Siruela.

Hernández, R. et al. (2010). Metodología de la investigación (5 ed.). México: McGraw-Hill. 
ISSN 0123-1294 | e-ISSN 2027-5358 | Educ.Educ. Vol. 22. No.1 | Enero-abril de 2019 | pp.103-119.

Universidad de La Sabana | Facultad de Educación

La ciudad de las ideas. [LaCiudaddelasIdeas]. (2010, abril, 26). Entrevista. La Ciudad de las Ideas. [Archivo de video]. Recuperado de https://www.youtube.com/watch?v=xJkPGSJLUAU

Levy, P. (2004). Inteligencia colectiva: por una antropología del espacio. Washington: Organización Panamericana de la Salud. Recuperado de http://inteligenciacolectiva.bvsalud.org/public/documents/pdf/es/inteligenciaColectiva.pdf

Márquez, M., Padua, D. y Prados, M. (2017). Investigación narrativa en educación, aspectos metodológicos en la práctica. En S. Rendón y J. Ángulo, Investigación cualitativa en educación (pp. 133-148). Buenos Aires: Miño y Dávia.

Meza, J. et al. (2011). Educación religiosa escolar. Naturaleza, fundamentos y perspectivas. Bogotá: Universidad Javeriana.

Meza, J. et al. (2013). Educación religiosa escolar en clave liberadora: elementos constitutivos. Revista Theologica Xaveriana, 63/1(175), 219-248. Recuperado de https://revistas.javeriana.edu.co/index.php/teoxaveriana/ article/view/9322

Meza, J. L. y Reyes, J. (2018). Pensar el objeto de estudio de la Educación Religiosa Escolar. Revista Electrónica de Educación Religiosa, 8(2), 1-24. Recuperado de http://reer.cl/index.php/reer/article/view/82

Meza, J. y Suárez, G. (2013). Educar para la libertad una propuesta de ERE en perspectiva liberadora. Bogotá: Universidad Javeriana.

Ministerio de Educación Nacional (1998). Indicadores de logros curriculares: hacia una fundamentación. Bogotá: MEN. Recuperado de http://www.mineducacion.gov.co/1621/articles-89869_archivo_pdf11.pdf

Ministerio de Educación Nacional (2006). Decreto 4500: Normas sobre la Educación Religiosa. Recuperado de http://www.mineducacion.gov.co/1759/articles-115381_archivo_pdf.pdf

Ministerio de Educación Nacional (2015). Decreto 1075: Decreto único reglamentario del sector educación. Recuperado de http://www.alcaldiabogota.gov.co/sisjur/normas/Norma1.jsp?i=62510

Ministerio del Interior (1998). Decreto 354: Convenio de derecho público entre el Estado colombiano y algunas entidades religiosas cristianas no católicas. Recuperado de https://www.mininterior.gov.co/sites/default/ files/decreto_354_de_1998.pdf

Páramo, P. (2010). La investigación en las ciencias sociales. Estrategias de investigación. Bogotá: Universidad Piloto de Colombia.

Peresson, M. (2004). Evangelizar Educando desde las áreas del currículo. Bogotá: Kimpres.

Peresson, M. (2016). Hacia una Educación Religiosa Escolar situacional y experiencial: Fundamentos epistemológicos, antropológicos, teológicos y metodológicos de la ERE. Bogotá: Servicio Catequístico Salesiano.

Poder Ejecutivo Nacional (1870). Decreto Orgánico de la Instrucción pública primaria. Bogotá. DOI: $10.17227 / 01203916.5024$ 
Poder Ejecutivo Nacional (1886). Constitución Política de Colombia. Bogotá. Recuperado de http://www.alcaldiabogota.gov.co/sisjur/normas/Norma1.jsp?i=7153

Remolina, G. (2017). Los fundamentos de una ilusión. ¿Dios y la religión, ilusión o realidad? Bogotá: Pontificia Universidad Javeriana.

Rueda, J., Medina, G., Ramírez, J., Villarreal, D., Corredor, D., \& Fonseca, J. (2015). Educación religiosa escolar en perspectiva liberadora. Civilizar: Ciencias Sociales Y Humanas, 15(28), 247-262. DOI: 10.22518/16578953.291

Sánchez, J. (2003). Filosofía y fenomenología de la religión. Salamanca: Secretariado Trinitario.

Tamayo, M. (2004). El proceso de la investigación científica. México: Limusa.

Torralba, F. (2010). La inteligencia espiritual. Barcelona: Plataforma Actual.

Unesco (2005). Convención sobre la protección y promoción de la diversidad de las expresiones culturales. París: Unesco. Recuperado de http://unesdoc.unesco.org/images/o014/001429/142919s.pdf

Universidad Popular Logroño. [Universidad Popular Logroño]. (2015, abril, 27). 04 Ponencia 1 Francesc Torralba. [Archivo de video]. Recuperado de https://www.youtube.com/watch?v=_kORyohJ7ql

Vasilachis, l. et al. (2006). Estrategias de investigación cualitativa. Barcelona: Gedisa.

Zohar, D. y Marshall, I. (2001). Inteligencia espiritual: la inteligencia que permite ser creativo, tener valores y fe. Barcelona: Plaza \& Janes. 